\title{
CONTEXTO SOCIAL: $O$ MUNDO DO TRABALHO, A FAMÍlIA E OS "ETERNOS" ADOLESCENTES
}

Mario Ester de Freitos

Este artigo é o resultado de uma palestra proferida num simpósio sobre a adolescência, ${ }^{\prime}$ atendendo a um convite que eu recebi com muita surpresa. Surpresa pelo fato de não ter uma formação específica nas áreas que normalmente se ocupam da questão da adolescência. No entanto, foi uma surpresa que, progressivamente, se transformou num prazer na medida em que esse convite traduz uma abertura acadêmica que ao meu ver é cada vez mais pertinente. Ou seja, diante de uma realidade cada vez mais complexa e multifacetada, é o esforço inter e multidisciplinar que pode nos conduzir a uma compreensão melhor do mundo em que vivemos.

A minha formação tem sido direcionada para o estudo das organizações e da administração privada e pública. Esses estudos sempre se beneficiaram da contribuição de várias outras disciplinas sociais e humanas, entre elas a Economia, a Sociologia, a Psicologia, a Antropologia e, mais recentemente, a Psicanálise. Dessa forma, é mais visível o aporte que o corpo teórico administrativo e organizacional tem recebido de outras disciplinas que o aporte que ele tem fornecido.

\section{Hoje, há um certo mal- estar manifestado pelas incertezas vividas nas sociedades do Ocidente e que se traduz, às vezes, pelas angústias identitárias e pelas tentativas de reconstrução, perplexidade ante as bifurcaçōes e busca de orientação.}

Não podemos esquecer, todavia, que o mundo do trabalho implica relações múltiplas com as diversas instituições da sociedade, pois os homens e as mulheres que todo dia vão para o trabalho não deixam em casa uma parte de si para tornarem-se apenas profissionais: eles continuam sendo pais, mães, filhos, maridos e esposas e, portanto, afetam o que ocorre no mundo do lar, no seio da família, e são por ele afetados. A esfera do trabalho reclama cada vez mais uma exclusividade, o que, certamente, não se dá sem causar um grande impacto na vida familiar e, especialmente, na forma de convivência com os filhos.

$O$ meu interesse pelo tema Adolescência surgiu de uma maneira que, eu diria, foi quase tangencial a uma questão maior do que aquela com a qual eu tive que me defrontar durante a elaboraçăo da minha tese de doutorado. ${ }^{2}$ Eu tentava responder a uma pergunta que era basicamente a seguinte: por que as empresas estāo assumindo cada vez mais o papel de ator central nas sociedades modernas? A investigaçăo que eu empreendi me levou à necessidade de conhecer vários autores fora da minha área específica e à constatação de uma crise de identidade na sociedade moderna que encerra vários aspectos, 
que eu gostaria de apresentar de uma forma mais ou menos breve.

Especialmente nos últimos cinqüenta anos, as sociedades modernas, particularmente as ocidentais, têm passado por um processo de mudancas extremamente acelerado e que comporta, entre outras características, a elevação do nível mundial de ensino e pesquisa, a "hegemonia" do capitalismo como o melhor sistema econômico, a tecnologia como uma forma de vida e a entrada maciça da mulher no mercado de trabaho. Cada uma dessas variáveis exerce influência sobre as demais e gera uma cadeia de implicações cada vez mais complexa quanto mais rápida é a sua interferência no mundo social. Os impactos dessas e de outras mudanças têm se feito sentir em todos os aspectos da vida e em todos os agentes do cenário social. Os universos da família, da religiăo, do trabalho, da escola, da moral, da ética e também da pátria têm passado por grandes modificações, que são em grande medida consequiências e causas daquelas variáveis.

A sociedade como um todo e as organizações têm sido sacudidas por essas transformações, mas especialmente os indivíduos e as famílias sentem o seu peso de maneira mais forte, ainda que de forma não muito palpável. Não se trata apenas de reflexos e ajustes às novas exigências que săo a eles colocadas, mas da necessidade de compreender e acomodar uma nova forma de vida, calcada em novos valores, significaçốes e referências que não estão ainda claras para ninguém.

Antes de entrarmos no universo específico da família, que vai conter alguns aspectos da discussão sobre a adolescência, eu gostaria de pontuar alguns argumentos a respeito dessa crise de identidade, ou melhor, crise no processo de identificação dos indivíduos, tendo como pano de fundo este século, mais precisamente a sua segunda metade.

Com a proposta de desenvolver uma abordagem pluralista sobre a questão da crise no processo de iden- tificação dos indivíduos nas sociedades contemporâneas, a ARIP Association pour la Recherche et 1'Intervention Psychologiques -, em Paris, promoveu um colóquio em $1989^{3}$ reunindo cientistas de várias especialidades: filósofos, sociólogos, psicólogos, psicanalistas, psicossociólogos, entre outros. Esse grupo desenvolveu uma perspectiva conjunta e apresentou algumas teses sobre as causas dessa crise ou, no mínimo, desse mal-estar nas sociedades de hoje.

\section{A sociedade hoje, tal qual está, não tem mais respostas para sua auto- \\ representação, o seu autoquerer $e$, socialmente falando, não tem mais como saber onde está o sentido vivido como imortal pelos homens e mulheres contemporâneos.}

Apresento, a seguir, alguns dos pontos que mais me chamaram a atenção:

Jacqueline Palmade agrupa quatro correntes:

- perda de fundamentos, transcendência, sublimação como perda de sentido; esfacelamento da religião, da moral, da ética, do sagrado; crise do saber e sua legitimaçāo; valores sublimes invadidos por valores de mercado;

- enfraquecimento dos vínculos sociais e surgimento de um novo individualismo, gerador da perda das referências indispensáveis à constituição do vínculo sociat;

- clivagem das identificações sociais, especialmente nas esferas tecnoeconômica, política e cultural, sendo que a primeira estaria contaminando as demais;

- fragilização das bases identitárias e suas variantes: perda da ancoragem do universo simbólico sustentado pela história, tradição, genealogia familiar, ou seja, um. núcleo estável e coeso; perda das mediações entre o psicoafetivo e 0 social; perda da relação de apoio sobre os dois pais, considerando a regressāo do casamento e a ambivalência nas relaçōes de longo prazo.

Jean Maisonneuve situa sua tese no âmbito das condutas e comportamentos, nos quais especialmente os ritos e rituais (particularmente os de passagem) tem deixado de cumprir as suas funções, existindo uma diluição das fronteiras entre as idades e etapas da vida. Essa confusão gera uma enorme dificuldade de identificação, altera as fontes de referências e de segurança dos indivíduos e grupos sociais.

Jean-Claude Rouchy acentua a fragilidade das fontes de identificação e dos grupos de filiação. Tanto os grupos primários (responsáveis pela constituição da auto-estima e da responsabilidade) quanto os secundários (a convivência com o outro, o diverso, a alteridade) estāo sendo esvaziados de suas funçōes e a passagem do intrapsíquico para o psicossocial está enfraquecida.

André Nicolaï nega que exista uma crise, mas assume a existência de um mal-estar, que é manifestado pelas incertezas vividas hoje nas sociedades do Ocidente. $\mathrm{O}$ mal-estar se traduz, às vezes, pelas angústias identitárias e pelas as tentativas de reconstrução, perplexidade ante as bifurcações e busca de orientação. Surgem três manifestações de mal-estar: o narcisismo das pequenas diferenças (tribos, segundo a denominação de Michel Maffesoli), o novo individualismo (idealização do sucesso pecuniário) e os intermináveis adolescentes, de Tony Anatrella, que detalharemos adiante. 


\section{Contraponto}

Castoriadis é, de todos os autores que participaram desse colóquio, aquele que carrega mais fortemente nas tintas e diz claramente que não apenas existe uma crise de identidade, como essa crise atinge um elemento central do processo de hominização social. O processo de identificação passa por vínculos que năo existem mais na sociedade ou estão caducos. Não é apenas uma crise de valores, mas uma crise das significações imaginárias sociais, ou seja, da sociedade no seu conjunto. Toda sociedade cria o seu próprio mundo elaborando justamente as significações que lhe são especificas. A sociedade hoje, tal qual está, não tem mais respostas para sua auto-representação, o seu autoquerer $e$, socialmente falando, não tem mais como saber onde está o sentido vivido como imortal pelos homens e mulheres contemporâneos. No mundo do cassino, da aparência, do vale pelo que se tem, a auto-representação de si e do social se empobrece e perde sentido.

É aqui, no meio desses questionamentos, que eu gostaria de incluir um outro aspecto do cenário: o mundo do trabalho. A supervalorização do primado econômico e do sucesso profissional coloca a esfera do trabalho como aquela que pode dar a referência global do indivíduo. Esse universo sofreu mudanças drásticas nos últimos anos, com o desaparecimento, o surgimento e a desvalorização de algumas profissões, uma elevação enorme do nível de cobranças do meio profissional e uma ameaça crescente de perda do emprego. Essa ameaça é oriunda, em boa medida, das reestruturaçōes nas organizaçōes, estimuladas por uma maior competitividade e pelas incorporações tecnológicas feitas, que, em vários setores, mais dispensa que precisa do trabalho humano. Esse contexto vai afetar diretamente o uni verso familiar, que também foi alterado radicalmente nestes últimos anos.

A questāo de estabilidade da família é hoje um dado incontestável. A queda dos índices de casamento, o aumento vertiginoso do número de divór- cios, a redução do tamanho da família e a redefinição do conceito de família nuclear são alguns dos sinais mais visíveis das mudanças ocorridas nesse contexto. Houve, ainda, uma grande mobilidade geográfica que transferiu para o anonimato das grandes cidades um enorme contingente populacional, que se afastou progressivamente de seus laços familiares e de vizinhança.

\begin{tabular}{|} 
A entrada da mulher \\
no mercado de \\
trabalho provocou \\
uma série de \\
alterações no quadro \\
familiar, que vai desde \\
a opção de não casar \\
até a opção de não ter \\
filhos.
\end{tabular}

A entrada da mulher no mercado de trabalho provocou uma série de alteraçôes no quadro familiar, que vai desde a opção de não casar até a opção de não ter filhos. Os movimentos dos anos 60 , que tinham a mulher como um de seus eixos temáticos, trouxeram à tona a discussão sobre um tratamento social mais igualitário, puseram em xeque o referente masculino e também reivindicaram o direito de decidir sobre o seu corpo, retirando da igreja e dos padres a grande influência sobre questões sobre a sexualidade e a não-manutenção de casamentos indesejados. Houve uma ruptura com o modelo pregado pelas avós, que dizia: "ruim com ele, pior sem ele".

Esse novo estilo de vida, orientado em grande medida, mesmo que năo exclusivamente, pela própria necessidade econômica de manter a família depois de uma separação ou divórcio, coloca uma nova exigência: a de cuidar da carreira. Mesmo uma grande maioria dos casais de hoje năo pode mais rescindir de um segundo salário para compor o orçamento familiar, isto dito apenas para nos atermos às razões econômicas. Certamente existem outras exigências tão importantes quanto as cconômicas, mas que não iremos detalhar.

$\mathrm{O}$ ambiente mais competitivo eleva o nivel de exigências sobre todos os segmentos profissionais, que disputam arduamente o seu lugar e a possibilidade de mantê-lo. Progredir no trabalho significa, hoje mais que em qualquer época, fazer-se necessário e fazer-se necessário significa estar apto a promoções e aproveitar as oportunidades que surgem. $O$ clima de ameaça de desemprego, a exigência cada vez mais forte de uma dedicação exclusiva, a sobrecarga de trabalho para os sobreviventes das reestruturaçōes e o ritmo cada vez mais acelerado exigido para se aprender as novas qualificaçôes são responsáveis por uma elevação do nível de estresse no mundo atual do trabalho. Quem quiser sobreviver está condenado a vencer e a apresentar resultados de produtividade recorde a cada dia.

Ainda que exista hoje uma melhor distribuição das tarefas domiciliares, a mulher é ainda a grande responsável pelo funcionamento da casa e pelo acompanhamento da educação dos filhos. Māes casadas e descasadas, que criam seus filhos sozinhas, se vêem ante a quase compulsoriedade de abrir mão de parte do tempo da licença-maternidade com receio de serem consideradas desatualizadas no seu retorno ao trabalho e de perderem o seu lugar tão dificilmente conquistado. Existe uma chantagem implícita, silenciosa, que leva a mulher a retornar, espontaneamente, mais cedo ao trabalho após o parto.

Os pais, quando estão presentes, também estão correndo na selva, trabalhando de doze a quatorze horas por dia (uma jornada de oito horas é hoje considerada por algumas empresas como um part-time job) ou ligados na rede da empresa, com o computador na sala de jantar ou no quarto. $O$ mundo do trabalho, hoje, coloca outras exi- 
gências além daquelas oriundas da presença física; a disponibilidade também deve ser exercida no lar, o que significa que, mesmo em casa, muitos pais estão ausentes. Estressados, cobrados, confusos, divididos, angustiados, acabam por desenvolver um comportamento escapista na ponta mais frágil. Esse escapismo pode ser traduzido em concessões unilaterais aos desejos dos filhos, em omissões e jogos de faz-de-conta. Dizer sim é muito mais fácil, mais cômodo, mais prático, mais econômico.

Sem muita saída para conciliar a vida nesses dois universos, que reclamam cada vez mais atenção, especialmente as mães (o problema é novo para elas) levam seus filhos do berço para a creche, o que gera um enorme sentimento de culpa e impotência. E é no sentimento de culpa que uma boa parte do relacionamento entre pais e filhos vai se apoiar daí para frente.

Sabemos que a socialização primária é aquela que ajuda a criança a conhecer limites, mas também a de constituição do laço afetivo, é importante na construçāo da auto-imagem e autoestima. A criança se forma em parte devido ao que lhe é dado, mas também em parte graças ao que lhe é recusado, pois se ela não aprende a lidar com o não ela se tornará mais frágil, não aprenderá a lidar com a frustração e o convívio externo. Supomos que, quando uma criança é privada dessa vivência, ela terá maiores dificuldades de superar as etapas que constituirão a sua personalidade.

A socialização secundária, que hoje ocorre cada vez mais cedo, regula a relação social, mas sem o apoio afetivo. $O$ convivio institucional nas mais tenras idades, através de creches e escolinhas, não pode substituir aquilo que é próprio do universo familiar. À medida que cresce, a criança de hoje vai assumindo uma agenda de compromissos semelhante à desempenhada por adultos, com atividades que cumprem mais a funçāo educativa equilibrada. As escolas, por mais bem preparadas que estejam (e elas não estão), não têm estrutura para assumir a tarefa própria dos laços primários. As crianças de hoje são estimuladas muito cedo a sentirem-se independentes, a aprenderem a se virar. Esse sentimento de independência é falso, pois uma criança ou adolescente que é alérgico à frustração não desenvolve o psiquismo necessário nem à sua autonomia nem à sua real independência.

\section{Para muitos adultos a necessidade de permanecer jovem e companheiro de seus filhos, náo assumindo - seu papel e a sua autoridade, é uma forma de evitar seus próprios conflitos psíquicos, inclusive com o superego parental.}

Sufocados pelo sentimento de culpa e impotentes para resolver a questão do tempo dedicado aos filhos, os pais tentam compensar a ausência assumindo um comportamento permissivo, não tendo coragem de dizer não, não impondo limites e proibiçōes, além de não afirmar ou assumir a sua autoridade. Entulhados com brinquedos e tranqueiras de todos os tipos, presos à televisão e cuidando sozinhos de si, os filhos dominam o território e invertem a chantagem familiar tradicional. Apoiadas num argumento extremamente falacioso, as crianças de hoje desafiam os pais simplesmente lhes dizendo que "não pediram para nascer", como se alguém nascido neste mundo tivesse feito o pedido. Os pais caem no ardil e podem passar o resto de seus dias pedindo desculpas por terem cometido o sacrilégio de não ter um consentimento assinado por "bebês-majestades".
Os pais da geração dos anos 60 (hoje um alvo fácil das reengenharias) demonstram uma grande incapacidade de assumir autoridade e de interiorizar o poder do pai. Diz-se hoje que vivemos em uma sociedade sem pais. Essa dificuldade frente à autoridade conduz a uma prática cada vez mais em uso, que ć a de considerar a família uma democracia. Ora, a família não é uma entidade política e nem tudo é negociável; existe nela uma desigualdade natural $\mathrm{em}$ relação a idades, experiências, maturidades, responsabilidades e história. Ver a autoridade como algo nocivo ou a ser evitado apenas ajuda a aumentar a confusão e a indiferenciação entre os membros da familia e seus papéis. São os próprios pais que desqualificam o papel da autoridade e dele abdicam; são eles que não estāo convencidos da sua autoridade e o demonstram; eles estão presos nas armadilhas que eles próprios criaram sem querer, tornando-se reféns dos filhos carentes. Seria necessário assegurar que o amor não está em risco, que as decisões que são tomadas não são contra os filhos, mas para eles. Se uma proibiçāo não é clara e não é compreendida, ela é sentida como injusta. $O$ casal deve concordar com relação a alguns pontos e a criança deve saber que a ordem não é de um dos pais, mas de dois. No caso monoparental a decisão deve ser consistente, ${ }^{4}$ o que implica reduzir ao máximo as mensagens contraditórias em relação aos problemas do mesmo tipo, pois, se para cada nuança a criança tem respostas diferentes e contraditórias, ela não conseguirá organizar um quadro referencial na sua cabeça e não desenvolverá a sua capacidade de resolver esse tipo de problema.

Em todas as épocas é comum a tentativa de corrigir erros da geração anterior. No que diz respeito à geração dos anos 60 , ocorre muito mais que um equívoco bem-intencionado. $O$ medo de repetir os erros de uma educação tida como repressiva leva muitos pais a adotarem uma atitude omissa, cujo resultado comumente é o inverso do que pretendem. Crianças e adolescentes precisam de limites, parâmetros, 


\section{Contraponto}

proibições e referências; precisam da aprendizagem do risco, ou seja, saber assumir as consequiências da opção feita diante da "lei". Muitos pais não percebem que, ao tentar não reproduzir o erro de seus pais na educação que dão aos seus filhos, estão apenas tentando "consertar" uma situação-fantasma antiga, que é exclusiva deles e de seus cadáveres. A relação com os seus fílhos não é a relação que eles tiveram com seus pais. Muitos pais não punem porque verdadeiramente são impotentes para assumir o poder da sua autoridade, outros porque têm medo de perder o amor dos fillhos ou arranhar a sua imagem no pedestal em que pensam estar colocados.

Segundo Tony Anatrella ${ }^{5}$ a adolescência é a idade privilegiada do século $\mathrm{XX}$, especialmente depois dos anos 50 . $O$ peso numérico dessa faixa etária na distribuição das idades de um país dá uma idéia de seu futuro promissor (ou dava, até pouco tempo atrás, quando o desemprego ainda não atingia essa faixa de idade). Mil pesquisas são feitas e divulgadas para saber-se a opinião dos jovens, como se comportam, o que consideram como desejável e o que é futuro para eles. Existe nas sociedades atuais uma supervalorização do jovem e da imagem jovem. Envelhecer é uma doença a ser evitada a todo preço.

O tempo da infância foi reduzido, pois, com a melhoria das condições de vida, saúde e nutrição, a puberdade ocorre mais cedo, a eclosāo de comportamentos sexuais também ocorre mais cedo e a adolescência se prolonga nos seus limites inferior e superior, indo dos 12 aos 30 anos. $O$ tipo de posicionamento dos pais, que fogem da autoridade, se modifica e assume um caráter mais informal, mais horizontal, mais próprio da confraria, dos companheiros, dos cúmplices.

Alicerçado no complexo de culpa, a perda do vínculo vertical traz consequências profundas na maneira de viver essa adolescência e no processo de individuação desses adolescentes. Os pais, por seu lado, buscando parecer modernos e melhorar os canais de comunicação com os filhos acabam adotando comportamentos (vestir-se, divertir-se) e atitudes (inclusive a linguagem) que são próprios dos filhos, dando origem a uma sociedade "adolescentrique", na qual as diferenças entre as gerações passam a ser negadas, reduzidas ou pseudo-eliminadas. Os modelos irmãos-irmãs, amigocúmplice, ou seja, horizontais, levam à constituição e manutenção de personalidades sem genealogia, sem incorporar as diferenças de geraçŏes, e não proporcionam identificações estruturantes, mas apenas identificações laterais e transitórias.

Quando a diferença das gerações é negada, é negada também a noção de passado, de tempo e de história, ou seja, o próprio sucesso de aprendizagem e educação perde o sentido. As referências vão se situar no hoje, no imediato, no agora, e mata-se a própria memória. No modelo horizontal a função educativa é exercida muito mais como uma forma de sedução, de persuasão ou de convencimento, pois ela tem difićuldade de expressar a lei. A figura do pai oscila em um meio caminho entre o tio e o irmão mais velho. A mãe-amigacúmplice escuta e faz confidências, como se o(a) filho(a) fosse um adulto com toda a sua maturidade psíquica e pudesse suportar o peso e a intensida de das experiências próprias da vida adulta. Confiança passa a ser uma questão de tudo dizer ao outro, independentemente se o outro pode ou não absorver o que é dito. Cada vez mais a maturjdade psíquica não é sincronizada entre o desenvolvimento corporal, a maturação afetiva, as modificações da personalidade, $o$ acesso ao pensamento formal, a inserçāo profissional e a consciência de responsabilidades.

Para muitos adultos a necessidade de permanecer jovem e companheiro de seus filhos, não assumindo o seu papel e a sua autoridade, é uma forma de evitar seus próprios conflitos psíquicos, inclusive com o superego parental. Adultos infantilizados parecem ser um caso mais grave que o de adolescentes infantilizados; eles vêem seus filhos precisando de ajuda e não admitem que eles próprios também estão carentes dela. Muito provavelmente năo se pode fazer muita coisa por um adolescente transgressor, egoísta, manipulador sem fazer algo pelos seus pais.

Por fim, estimulados desde a mais tenra idade a fazer contatos e a viver em grupos instáveis, móveis e transitórios, os adolescentes acabam desenvolvendo contatos numa rede de estranhos íntimos que vai se constituir num grupo-tribo de referência. $O$ narcisismo próprio da adolescência, ao invés de ser promotor de diferenciação e individuação do sujeito, pode levá-lo ao conformismo, ao desaparecimento de si nas relaçōes grupais. Aqui o narcisismo atinge um paradoxo bem singular: ser igual a todo mundo, encontrar-se nos outros para dissolver a incapacidade de ser um simesmo. Freud, há muito tempo, já nos falou dos perigos do narcisismo das pequenas diferenças...

\section{NOTAS:}

1. Palestra proferida no simpósio "As vicissitudes da adolescência", promovido pelo Departamento de Psiquiatria da Universidade Federal de São Paulo, em 23 de agosto de 1997.

2. Tese apresentada à EAESP/FGV sob o título Cultura organizacional: seduçāo \& carisma, defendida em abril de 1997

3. Ver o número 5 da Revista Connexions, intitulado Malaise dans I'identification, Paris, Erès, 1990/1.

4. Ver Dr. Delaroch, Patrick. Parents: osez dire non! Paris: Albin Michel, 1996.

5. Ver Anatrella, Tony. Interminables adolescences: les $12 / 30$ ans. Paris: Cerf/ Cujas, 1988.

Maria Ester de Freitas Professora do Departamento de Administração Geral e Recursos Humanos da EAESP/FGV. 